\begin{tabular}{|l|l|}
\hline & \\
\hline &
\end{tabular}

RESENHA

\title{
JERÓNIMO, Miguel Bandeira; MONTEIRO, José Pedro. Histórias(s) do presente. Os mundos que o passado nos deixou. Lisboa: Público/Edições Tinta-da-China, 2020.
}

\section{Vitor de Sousa ${ }^{1}$}

orcid.org/0000-0002-6051-0980 vitordesousa@gmail.com; vitordesousa@ics.uminho.pt

Recebido em: 05/03/2020. Aprovado em: 11/01/2021. Publicado em: 30/04/2021.

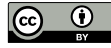

Artigo está licenciado sob forma de uma licença Creative Commons Atribuição 4.0 Internacional.
Logo no início de Histórias(s) do Presente. Os mundos que o passado nos deixou, Miguel Bandeira Jerónimo e José Pedro Monteiro, ambos investigadores do Centro de Estudos Sociais da Universidade de Coimbra, deixam claro que "o cepticismo é uma forma sã de viver civico, não apenas um inabalável princípio científico". Na introdução do livro, os autores interrogam o passado e procuram pistas para interpretar com rigor a atualidade, observando que "o conhecimento da história não é um elixir contra a maldade ou contra o desvario" (JERÓNIMO; MONTEIRO, 2020, p. 12). A dinâmica, observam, vai mesmo em sentido contrário, já que os usos da história serviram quase sempre "propósitos bem pouco edificantes". A atestá-lo, está o facto de o conhecimento não impedir o ódio. Dessa forma, induzir dúvidas onde só parece haver certezas, como propõem na Introdução da obra, será já uma tarefa e tanto (JERÓNIMO; MONTEIRO, 2020, p. 12).

O livro agrupa, numa versão atualizada, a série de trabalhos dados à estampa no jornal diário português Público, em 2017 e 2018, (12 ensaios e 12 entrevistas a reputados especialistas internacionais) sobre eventos e processos históricos que marcaram o nosso passado, e sobre os legados que nos deixaram. Neste rol, encontram-se quase todos os assuntos que preenchem a atualidade informativa de há anos a esta parte: a crise dos refugiados, o racismo, a globalização, os nacionalismos, os usos dos véus, as fake news, os abusos da história. Através da exploração das histórias plurais saídas dos campos de concentração, da emergência de um discurso dos direitos humanos ou das políticas do medo e da histeria coletiva organizada, hoje tão presentes, convida-se o leitor a tentar perceber como se chegou até aqui, propondo-lhe um olhar do que aconteceu de forma a poder imaginar-se um futuro melhor.

O livro integra uma dúzia de capítulos e, dentro de cada um deles, é apresentado um ensaio e uma entrevista sobre determinada temática. Logo a abrir, temos o ensaio intitulado "Por uma vigilância dos usos e abusos da história" (JERÓNIMO; MONTEIRO, 2020, p. 25) e é entrevistada Elizabeth Buettner, professora de Histórica Contemporânea da Univer- 
sidade de Amesterdão, "Mesmo hoje, minorias nascidas na Europa são 'imigrantes de segunda geração'" (JERÓNIMO; MONTEIRO, 2020, p. 36). Segue-se "A brutalidade em nome da ordem, a ordem em nome da brutalidade"(JERÓNIMO; MONTEIRO, 2020, p. 51), sendo a entrevista feita a Dan Stone, professor de História Moderna na Royal Holloway, Universidade de Londres ,"Não precisamos de chamar aos campos de refugiados campos de concentração para saber que há algo de errado na sua existência"(JERÓNIMO; MONTEIRO, 2020, p. 64); "Uma história da 'exploração edificante'" (JERÓNIMO; MONTEIRO, 2020, p. 75), em que é entrevistado Joseph Hodge, professor de História na West Virginia University, EUA, "Há paralelos entre desenvolvimento e a missão colonizadora" (JERÓNIMO; MONTEIRO, 2020, p. 89); "Por uma 'educação sentimental' persistente", com entrevista a Samuel Moyn, professor de História do Direito na Universidade de Yale (EUA), "Os direitos humanos permitiram que os ocidentais regressassem a locais que já não podiam governar" (JERÓNIMO; MONTEIRO, 2020, p. 101).

Há um ensaio dedicado às fake news intitulado "As origens dos 'factos' plantados e das notícias falsas", sendo a entrevista feita a David Miller, professor de Sociologia na Universidade de Bath (UK), "As fake news são dominadas pelos governos ocidentais e pelas multinacionais", (JERÓNIMO; MONTEIRO, 2020, p. 140); e outro, denominado "Os mundos da ansiedade" (JERÓNIMO; MONTEIRO, 2020, p. 147), em que é entrevistada Joanna Bourke, professora de História no Birbeck College, na Universidade de Londres, "Teólogos, políticos, jornalistas, médicos e serviços psicológicos dependem do nosso pavor" (JERÓNIMO; MONTEIRO, 2020, p. 162).

Num capítulo sobre os anos 60 do século XX, "O momento dos 60: nem apolíneo, nem dionisíaco" (JERÓNIMO; MONTEIRO, 2020, p. 171), é entrevistada Samantha Christiansen, professora assistente na Universidade de Marywood, Pensilvânia (EUA) "O verdadeiro impacto dos sixties foi a normalização da ideia de que nós podemos mudar o mundo" (JERÓNIMO; MONTEIRO, 2020, p. 187); no capítulo seguinte, "O que revelam os véus" (JERÓNIMO; MONTEIRO, 2020, p. 197), há uma entrevista a Joan Wallach Scott, professora emérita do Instituto de Estudos Avançados na Universidade de Princeton (EUA): "O movimento \#MeToo revelou que as mulheres foram educadas para acomodarem o poder masculino, e não para o recusarem" (JERÓNIMO; MONTEIRO, 2020, p. 213). Outro dos ensaios tem por título "Os refúgios da história" (JERÓNIMO; MONTEIRO, 2020, p. 221) , sendo entrevistado Peter Gatrell, professor na Universidade de Manchester (Inglaterra), "Hoje há muito menos enfoque na protecção dos refugiados e muito mais na protecção do Estado de uma suposta 'invasão'" (JERÓNIMO; MONTEIRO, 2020, p. 236); contabilizando-se, ainda, o ensaio sobre "A universalização do particular, a particularização do universal" (JERÓNIMO; MONTEIRO, 2020, p. 245), com entrevista a Quinn Slobodian, professor de História no Wellesley College (EUA), "A mais eficiente critica ao globalismo neoliberal não veio da esquerda, mas da direita" (JERÓNIMO; MONTEIRO, 2020, p. 262).

O penúltimo ensaio denomina-se "O cinto do mundo" (JERÓNIMO; MONTEIRO, 2020, p. 275) e é entrevistado Robert Vitalis, professor de Relações Internacionais e Ciência Política na Universidade da Pensilvânia (EUA), "Deixei de me surpreender com os mitos ou verdades doutrinárias que os professores repetem sem questionarem" (JERÓNIMO; MONTEIRO, 2020, p. 289). O livro termina com o ensaio "Um só mundo... ou nenhum", (JERÓNIMO; MONTEIRO, 2020, p. 297) e a entrevista é feita a Sandrine Kott, que tem uma obra extensa na história do estado social e das relações de trabalho na Europa, "É ilusório pensar que o Estado nação constitui um casulo protector contra a globalização" (JERÓNIMO; MONTEIRO, 2020, p. 312); e com uma útil "breve bibliografia temática" (JERÓNIMO; MONTEIRO, 2020, p. 323).

Como se pode ler na introdução da obra, o objectivo da investigação era o de contribuir para uma esfera pública "viva, atenta, mas, sobretudo, mais democrática e inclusiva, e menos desigual" e, seguramente, menos violenta e dependente do ruido "que confunde agressividade com convicção, gritaria com debate de ideias" (JERÓNIMO; MON- 
TEIRO, 2020, p. 10). No entanto, neste particular, os autores assumem ter "falhado redondamente" já que, mais de dois anos depois da publicação da série de reportagens, "o balanço dos termos do debate público em Portugal e no mundo ocidental, não é propriamente animador" (JERÓNIMO; MONTEIRO, 2020, p. 10), bastando olhar em volta ou, de forma mais diferenciada, estar atento aos média, especialmente aos televisivos.

Como os autores bem sintetizam, não se vislumbram sinais de melhorias, com os "trombeteiros" a continuarem "entusiasmados, à sexta e ao sábado, com plena consciência de contribuírem para agudizar o que dizem pomposamente querer transformar, isto é, a qualidade do debate público" (JERÓNIMO; MONTEIRO, 2020, p. 10). Não obstante, como assinala Rémy Rieffel, a expressão "cultura mosaico" parecer traduzir de forma fiel a relação entre os média e a cultura, mesmo que não faça "nenhum juizo precipitado sobre qualquer uniformização do pensamento ou qualquer desperdício de sentido" (2003, p. 106).

Trata-se de um quadro que se traduz em constatações até há bem pouco tempo impensáveis, relativas à igualdade de género, à raça ou a aspetos socioeconómicos, "que retornam de forma virulenta do sistema mediático" e, por conseguinte, do sistema social. O que também acontece em relação a Portugal. Tudo isto, segundo os autores, demonstra que os que defendiam o fim da história, exageraram no anúncio. E, em sentido contrário aos prognósticos, ela está mesmo em pleno desenvolvimento, o que nunca deixou, de resto, de acontecer: "Também por isso, a tentação de ressuscitar 'lições da história', a usar de modo imediato e confiante, aflora com inusitada frequência" (JERÓNIMO; MONTEIRO, 2020, p. 10).

O que quer dizer que a analogia na história ou o seu trágico encerramento, não gera apenas ignorância, mas impede a abertura de novos caminhos, mesmo que pouco conhecidos e contraditórios, "que certamente pouco podem face ao consolo e elogio do grupo, social, académico, profissional" (JERÓNIMO; MONTEIRO, 2020, p. 10-11). De forma mais taxativa, Miguel Bandeira Jerónimo e José Pedro Monteiro assinalam que "a transposição de categorias do passado para identificar os seus correlatos presentes pode servir para invocar a história como guia do presente e estabelecer causalidades imediatas". Não serve, no entanto, a imaginação política e social, e muito menos se "alicerça numa forma particularmente ágil e refinada de pensar a história" (JERÓNIMO; MONTEIRO, 2020, p. 11).

Olhando, então, para a história, de forma banal, sublinhando a irrepetibilidade dos seus momentos, bem como o facto de eles serem irreproduziveis, ou a partir de modelos de causalidade simplificados e preditivos, os autores assinalam existir espaço para se pensar a partir de outras preocupações. Mesmo que, como acontece com outros modos de produzir conhecimento, "não te[nha] de ser imediatamente útil" e muita da sua utilidade se revele mesmo inútil. $E$, perante a ansiedade política, institucional e, também, académica, referem ter que se reiterar esse facto, "que leva a subordinar a produção de conhecimento a critérios de 'aplicação', de 'inovação', de 'mercado' ou de 'tecnologia', ou até de uma dada 'causa maior'" (JERÓNIMO; MONTEIRO, 2020, p. 11). O que se cruza com as ideias de Daniel Innerarity (2019), que liga o pouco entendimento de uma sociedade às medidas tendentes a que ela seja mensurável já que, como observa, quase tudo se pode quantificar, num verdadeiro regime da omnimetria.

Voltando à história, ela pode, segundo os autores, em certa medida, e certamente em diálogo frutuoso com outras disciplinas, "fornecer alguns instrumentos para pensar de modo crítico e inovador, abrindo espaço para novas e melhores interrogações e, assim sendo, apontando para outras respostas possiveis" (JERÓNIMO; MONTEIRO, 2020, p. 11). Mesmo que ainda se olhe para ela como se fosse construída entre bons e maus, sendo que é muito mais complexa do que isso.

Trata-se, por isso, de um desvio de uma questão que é urgente colocar e que se prende com a situação da pesquisa histórica, já que o passado deveria ser estudado através do cruzamento da história com as ciências sociais em geral - tal como defendem Miguel Bandeira Jerónimo e José Pedro Monteiro -, assente em fontes e através do desenvolvimento 
de uma prática analítica que impeça uma prática moralista e o presentismo, com o risco de que tudo o que é da história se comprima em história contemporânea (HARTOG, 2003).

Segundo Jerónimo e Monteiro, o trabalho que desenvolveram durante mais de um ano, assente no envolvimento de reputados especialistas nas mais diversas áreas que dominam a atualidade social, partiu de problemas ou de processos concretos, na tentativa de inquietar os leitores, de modo a que se questionassem sobre como se chegou ao produto final, propondo uma leitura particular das histórias que formaram o presente. Procuraram, assim, responder a algumas inquietações sentidas na contemporaneidade, munidos da investigação daquilo que já passou, como foi o caso da denominada "crise" de refugiados, em que recordaram que a última "crise" vivenciada de dimensões semelhantes tinha acontecido na Europa. O que não foi feito, no entanto, de forma a procurar no passado estímulos para a empatia já que, "quem precisa de estímulos para a empatia não precisa de historiadores, mas de outros profissionais" (JERÓNIMO; MONTEIRO, 2020, p. 12).

O objetivo foi disponibilizar uma perspetiva diferente da história, a partilhar com o público não especializado. Pretendeu-se, desde o início, ultrapassar as barreiras do denominado "nacionalismo metodológico", que não é novo, mas que levanta muitas questões quando se constata que se trata de uma tarefa urgente.

Assim, os ensaios "procuraram não só dar espaço a diferentes geografias, como ligá-las em narrativas que procuram mostrar a independência e a multitude de conexões, nem sempre óbvias, como aspecto central da história". A título de exemplo, referem a existência de "acontecimentos em África que moldaram a Europa e ideias que viajaram do Extremo Oriente até à América Latina", o que deve implicar um distanciamento em relação a "modelos baseados em 'centros' e 'periferias' em 'norte' e 'sul', ou de perspectivas difusionistas, incapazes de pensarem senão no modo unidirecional e linear" (JERÓNIMO; MONTEIRO, 2020, p. 21).

De resto, a história não deve ser pensada de forma linear, mas que olha de forma retroativa para os factos que estão no cerne da reflexão dialética, em sentido do conhecimento dito absoluto. O que assenta na ideia de Hegel (2018), de que a verdade não é estática, mas resulta da consciência dos momentos contraditórios que se superam num movimento dialético, em direção ao conhecimento dito "absoluto".

É dessa forma que o passado colonial pode revelar-se problemático, mesmo que Miguel Bandeira Jerónimo e José Pedro Monteiro assinalem que tendo sido com o fim dos impérios formais no mundo, que decorreu dos dois conflitos mundiais, foi apenas com a "descolonização global que a solução imperial se tornaria, politica e legalmente, inaceitável como forma de organização societal e politica" (JERÓNIMO; MONTEIRO, 2020, p. 23). O facto é que a ideia de colonialismo passou a ser encarada como coisa do passado, o mesmo se passando com o racismo: "Nalguns casos, de um passado cada vez mais distante, chegando ao ponto de negar o racismo no Estado Novo português, por exemplo". Passando por cima dessa alegada ignorância (simulada ou genuína), a série de trabalhos agora publicada em livro, "procurou sublinhar como os modos imperiais de governar a diferença marcaram o século pretérito, deixando legados que ainda hoje se fazem sentir" (JERÓNIMO; MONTEIRO, 2020, p. 23).

Trata-se, contudo, de um assunto que esteve sempre presente no desenvolvimento dos estudos constantes do livro, a par das "tentativas de romantizar uma suposta excepcionalidade miscigenadora portuguesa", que persistem, "tanto na esfera pública como em demasiados sectores da academia, amiúde de forma dissimulada, frequentemente para obter instrumentalmente apoios desta ou daquela instituição estatal ou privada" (JERÓNIMO; MONTEIRO, 2020, p. 24).

Foi, também, para contrariar o modo como o elemento "colonial" tem vindo a ser pensado em certos círculos, "substituindo o estudo da história pelo estudo da 'memória' ou de uma qualquer intervenção artistica contemporânea" que os estudos foram desenvolvidos. "Ao contrário do que vários arrivistas e oportunistas crêem ou pretendem fazer crer, os debates sobre estes elementos 
imperiais e coloniais são antigos, ricos e diversos, disputados, sem consensos", sendo que "a lengalenga dos silêncios, que só agora alguns, bravos e originais, conseguem enfrentar, é insustentável empiricamente", sublinham os autores. Ou seja: a história dos impérios coloniais europeus não é uma história antiga, estando visivel "nos nossos quotidianos, assim queiramos olhar para eles com alguma seriedade e profundidade" (JERÓNIMO; MONTEIRO, 2020, p. 24).

\section{Referências}

RIEFFEL, Rémy. Sociologia dos media. Porto: Porto Editora, 2003.

INNERARITY, Daniel. Política para perplexos. Porto: Porto Editora, 2019.

HARTOG, François. Regimes d'historicité: presentisme et experiences du temps. Paris: Seuil, 2003.

HEGEL, Georg Wilhelm Friedrich Filosofia da história. Brasilia: Editora Universidade de Brasilia, 2008.

\section{Vitor de Sousa}

Doutor em Ciências da Comunicação pela Universidade do Minho (UMinho), em Braga, Portugal; investigador do Centro de Estudos de Comunicação e Sociedade (CECS), em Braga, Braga, Portugal.

\section{Endereço para correspondência}

Vitor de Sousa

Universidade do Minho

Centro de Estudos de Comunicação e Sociedade, ICS-Instituto de Ciências Sociais

Campus de Gualtar

4710-057

Braga, Portugal 